\title{
The Impact of the Participation Rate - Whatever it is - on University Enrolment
}

\author{
A.L. DARLING*
}

\begin{abstract}
In the period from 1960 to 1976 the participation rate in university education increased dramatically and has since fallen. During this same period the size of the university age group doubled, so there was a period of great expansion in university enrolment. Population projections show a decline of the order of $20 \%$ in the size of the university age group between 1982 and 1996, and many believe that university enrolments must inevitably drop too, although the participation rate will be a major determinant of what happens. The factors which influence participation rates using the period 1960 to 1978, and the way in which participation rates are measured are examined. This is then applied to a discussion of the level of undergraduate enrolment in the period to 1996.
\end{abstract}

\section{RÉSUMÉ}

De 1960 à 1976 le taux de participation dans les études universitaires a augmenté d'une manière spectaculaire. Depuis lors il est tombé. Pendant cette même période le nombre de la population en âge de fréquenter l'Université a doublé, de façon qu'il y a eu une grande augmentation dans les inscriptions. Les études qui ont été faites sur la population montrent qu'entre 1982 et 1996 il y aura une diminution de l'ordre du 20\% dans le nombre des personnes qui ont l'âge requis pour fréquenter l'Université. Par conséquent, l'on croit que les inscriptions doivent inévitablement diminuer aussi, bien que le taux de participation soit le facteur déterminant de ce qui arrive. Les facteurs qui influencent les taux de participation pendant la période de 1960 à 1978 et le mode de calcul des taux de participation sont examinés. Ceci, par la suite, fait l'objet d'une discussion sur le niveau d'inscription aux études sousgraduées dès maintenant à 1996.

*Registrar, McMaster University. 
Until fairly recently it was anticipated that university enrolments would continue to rise until 1982-83 and decline thereafter as the size of the 18 to 24 age group decreased.

Declining enrolments are already a fact and the major concern now is not whether enrolment will decline but by how much. The data used in this paper will relate mainly to Ontario primarily because of the availability of system wide data and the author's own experience, but the discussion is more generally applicable.

Only two years ago the Ontario Council on University Affairs was questioning how the Ontario university system might cope with increases in enrolment of anywhere from 12 to $27 \%$ between $1975-76$ and 1982-83. (OCUA, 1977) In the Introduction to the Third Annual Report the Council presented four possible enrolment forecasts, although they were presented with the caveat that "enrolment forecasts are projections not prophecies". In the discussion accompanying the forecasts, it was noted that there were factors that might cause the actual experience to differ from the projections:

1. ". . admission to many programmes at many institutions has become highly selective. ..." (p. 7);

2. ". . it is anything but prudent to assume that further growth is in the interest of the university system. ..." (p. 12);

3. ". . the outlook for the coming three decades is for reduced growth in employment opportunities for university graduates. ..." (p. 13);

4. ". . marginal changes either in admission standards or in requirements for in-course academic standing can have a dampening impact on enrolment growth...." (p. 14).

Also available at that time was a forecast developed by Zsigmond and others of Statistics Canada which included projections which accounted for a large number of variables. The most likely combination of those variables forecasted a peak in full-time undergraduate enrolment in 1982 which was $20 \%$ above the level current at that time. (Zsigmond, 1976) The series of projections by Zsigmond suggested that enrolment might grow by anything from 11 to $33 \%$. The probability of the university system experiencing large growth such as projected in some of the models was questioned in some quarters. For example, the brief from McMaster University in the spring of 1977 to the Ontario Council in University Affairs stated that the higher forecasts were unrealistically high for a number of reasons:

1. a large proportion of the undergraduate places in Ontario universities were in programmes already constrained by enrolment limitations;

2. the reintroduction of a core curriculum in the high schools might reduce the numbers who would be qualified to enter universities;

3. the general economic outlook might limit an increase in the female participation rate and also cause more students to seek an education at a college of applied arts and technology; and

4. the lack of job opportunities for graduates from general arts and science programmes would probably result in there being little growth in these programmes. (McMaster, 1977)

Furthermore, the brief went on to state that it was the expectation that the peak would occur sooner than forecast and that there were factors that might precipitate a more rapid decline than had been anticipated. A survey of high school principals conducted 
39 The Impact of the Participation Rate - Whatever it is - on University Enrolment

by the University had suggested that Year I enrolments would begin to decline in the fall of 1978 rather than 1979 or 1980 . In addition, some universities were experiencing a shift from 4-year programmes to 3-year programmes in the arts and sciences.

In the fall of 1977 full-time undergraduate enrolment decreased by almost $3 \%$ from the previous year. In commenting upon this in its Fourth-Annual Report, the Ontario Council on University Affairs noted that the participation rate, expressed in terms of the 18 to 24 age group, had dropped to approximately $12.5 \%$ in $1977-78$ as compared to about $13 \%$ in $1975-76$. It was noted that the decrease in the rate reflected both the dropout of students in the upper years of university and a decreased intake, and further that the information available suggested that the freshman intake would drop again in 1978 . It was pointed out that a further $2 \%$ drop in enrolment would reduce the participation rate to $12 \%$, ". . . which was the rate for the period 1971 to 1974 ..." (OCUA, 1978 p 7)

University enrolment again declined in the fall of 1978 and in its Fifth Annual Report the Ontario Council on University Affairs noted that a drop of about $25 \%$ from the then current enrolment level "should not be unexpected". (OCUA, 1979 pp 9-10) It was suggested that such a decline should be viewed within the perspective of the ". . extraordinary increase which occurred during the past 20 years. Enrolment levels in 1996 may well only return to the level experienced in 1972 . . " (OCUA, $1979 \mathrm{p} \mathrm{10)}$ ) The report went on to state that

... Since 1960 the growth of the 18 to 24 age group has been approximately $108 \%$. In addition to the increase in the number of young people of the usual age to attend university, the participation rate also increased. Full-time undergraduate university attendance expressed as a percentage of the 18 to 24 age group increased from $5.4 \%$ in 1960 to a high of $13 \%$ in $1975-76$. (OCUA, 1979 p 25)

It was also estimated that the participation rate had dropped to $11.5 \%$ in. 1978-79. It was noted that the undergraduate enrolment decline had been concentraged primarily in the arts and sciences and was not distributed evenly among the universities ( $p 25$ ), that many of the professional programmes had enrolment ceilings which enjoyed a student demand in excess of their capacity ( $\mathrm{p} 26$ ), and that in the future enrolment was unlikely to decline evenly across the system ( $\mathrm{p} 28$ ). The possibility was also raised that ". . . an improved economy could produce a manpower shortage in 6 to 8 years' time and university graduates would be in greater demand..." (p 22).

In a report released in November, 1978 the Ministry of Colleges and Universities of Ontario attempted to assess the potential impact of high school enrolment changes on post-secondary education on a regional basis. (MCU, 1978) It was pointed out that over $70 \%$ of university freshman enrolments are derived from students who enter directly from the high schools of Ontario and that the anticipated decline in high school enrolment in the period $1976-91$ was expected to be more than $22 \%$. It was noted, however, that the implications of such decline for post-secondary education are more difficult to assess than for the elementary and secondary sectors, since participation in post-secondary education is voluntary. Nevertheless, the possibility that post-secondary enrolments might decline by the order of $20 \%$ in the period to 1991 was implied.

In February, 1979 Statistics Canada published a set of projections of Canada's school age population to the turn of the century, The Class of 2001 (Clark, Devereaux, Zsigmond, 
1979). The set of projections resulted from different assumptions about fertility rates and migration patterns; Projection 3 was favoured as the most reasonable for the short term, although readers were advised to make the choice according to the unique conditions within each province. In the case of Ontario Projection 4 would appear to be a more reasonable projection, since it assumes a net immigration of 24,400 per year, whereas Projection 3 assumes a net immigration of 43,300 . There has been a marked change in migration patterns in Canada since the original energy crisis of 1973-74, and the migration figures used in Projection 4 are more consistent with those experienced in Ontario since 1974. In Projection 4 the size of the 18 to 24 age group is shown to rise by $11.0 \%$ between 1976 and 1983, the peak year, and to decline by $19.9 \%$ between 1983 and 1996 . Overall the projected decrease in the period from 1976 to 1996 is $11.2 \%$. In the commentary it is pointed out that post-secondary education is a matter of choice affected by the social and economic climate, although it is argued that the demographic trends of the 18 to 24 age group from which $80 \%$ of full-time post-secondary students are drawn are valuable indicators of the future nember of post-secondary students. However, it is emphasized that

...projections are not predictions. They indicate the direction and magnitude of possible developments, based on past and present circumstances and assumptions about future trends in important variables (i.e. fertility, migration, etc.). They must be evaluated in light of the conditions when they were produced. Subsequent changes can alter the shape of what is projected... (p 15)

In attempting to assess what will happen to university enrolments in the longer term one obviously has a number of options from which to choose. It is obvious that one cannot approach this realistically purely by making mechanistic projections but one must make some attempt to examine the factors that will affect the participation rate, however it is expressed. The Fifth Annual Report of OCUA explained the enrolment growth between 1960 and 1978 both by the $108 \%$ increase in the size of the 18 to 24 age group and by the increase in the participation rate from $5.4 \%$ through a high of $13 \%$ in $1975-76$ to $11.5 \%$ in $1978-79$. A further 18 years from 1978 takes one to the year 1996 which is the year in which the trough of the size of the 18 to 24 age group occurs in Projection 4 presented in The Class of 2001. In comparison to the period 1960-78, the period 1978-96 does not bring with it demographic changes of the magnitude experienced in the earlier 18 year period. A $15 \%$ change in the size of the 18 to 24 age group may in retrospect look trivial when compared to significant changes in the participation rate, and fluctuations in participation rates will influence enrolments more in the future than they did in a period when the size of the university age group was also changing rapidly. It may be desirable, therefore, to re-examine the period 1960-78 to gain insight into why the participation rate changed, to review the use of a participation rate expressed in terms of the 18 to 24 age group, and to speculate on those factors which influence participation.

\section{0-78: The Period of Growth}

For most of this period accessibility to higher education was a major government objective. While there has never been a retraction of the stated objective, it is interesting to examine 
41 The Impact of the Participation Rate - Whatever it is - on University Enrolment

how over time the actions of government have either enhanced or detracted from the attainment of the stated objective.

There is no doubt that enrolment has increased dramatically in this period, but one must take care not to make too hasty a comparison because the statistical data are not always comparable. In examining enrolment data one is tempted to think that the published statistics are perhaps better a statement of how higher education was organized in the particular year than they were a statement of how many students were engaged in postsecondary education. This can perhaps be best illustrated by taking the field of education . In 1965-66 there were 13 teachers' colleges in which 5,913 students were registered; by 1968-69 these same 13 teachers' colleges enrolled 9,277 students. In 1966 the Minister's Committee on the Training of Elementary School Teachers recommended:

1. that by approximately 1975 all elementary teachers have degrees, and

2. that teacher training be placed within the universities.

Later, in September 1969, the admission standards for entry to the one year certificate programmes were raised to the same as those for entry to university. In 1969.70 the 13 teachers' colleges were reduced to 11 and the enrolment to 7,896; the two colleges which had disappeared had been incorporated into the local university as Faculties of Education. This trend continued during the 1970s until 1978-79 when only two teachers' colleges remained and they were closed at the end of that academic year. Enrolment in Faculties of Education peaked in 1976.77 at over 5,500, and it is obvious that the inclusion or exclusion of large groups such as that described and other groups can affect one's perception of how rapid the growth in enrolment has been.

The degree of detail presented in the statistics varies greatly. In 1960 there were fewer institutions and the expenditure from the public purse was less and not highly visible. As expenditure grew and became more visible, more data were requested and reported. The advent of formula funding in 1967-68 placed a new emphasis on enrolment data. Nevertheless, inconsistencies still abound because of the inclusion of different groups, different definitions of full-time students, and different reporting dates. New groups are included in more recent statistics just as happened with the education students. For example, the statistics of the Ministry of Colleges and Universities of Ontario include 2,504 medical interns and residents for the first time in 1976; 8,745 students at Ryerson Polytechnical Institute for the first time in 1975; and 1,034 students at the Ontario College of Art for the first time in 1974. In some cases enrolment at private institutions or in theological programmes were included or excluded according to the view that prevailed at the time. With knowledge of these major structural changes that have occurred in the data sets, one must view with skepticism any sweeping statement which makes a direct comparison between participation rates at different points in time, particularly where the source data from which the rates have been calculated are not available.

Perhaps the most visible commitment of the government to its policy of accessibility was the building of a host of new universities. Following the establishment of some institutions in the late 1950s, came Lakehead in 1962, Guelph, Brock and Trent in 1964, the Scarborough Campus of the University of Toronto in 1965, and the Erindale Campus of the University of Toronto in 1967. In 1964 the private Assumption University became the public University of Windsor, and similar transformations occurred in 1968 and 1973 


\section{A.L. Darling}

when the University of Ottawa and Waterloo Lutheran University (now Wilfrid Laurier University) became public institutions. The creation of new campuses which were geographically dispersed made university attendance easier for many.

Governments pursued their policies of increased accessibility by encouraging universities indirectly to undertake certain actions through financing mechanisms. In the early 1960 s the federal contribution accounted for about $20 \%$ of university expenditures, but in the period from 1967-68 to 1976-77 when the Federal Provincial Fiscal Arrangements Act was in force approximately $50 \%$ of the university's operating expenditures were funded by the Federal government. (Statistics Canada 1978 p 30) During this period, the commitment of provincial governments to the policy of accessibility was reinforced by a similar commitment from the Federal government. The Act expired on March 31, 1977 at which time some of the tax points were transferred to the provinces and the remainder of the payment is made as a per capita cash grant which will increase in relation to the gross national product. This change in fiscal arrangements coincided with the time when provincial governments were actively seeking to restrain the growth in public expenditure.

The introduction of formula funding in 1967-68 represented a major change, and also served, perhaps unwittingly, as an inducement for the universities to expand. Universities were financed on a formula related to enrolment so that the greater one's enrolment the greater one's income. If the marginal cost of adding students was less than the incremental income, the formula funding served as a means to provide money to fund new programmes and new developments.

The government found itself committed to an open-ended funding mechanism and the universities experienced budgetary problems when enrolments failed to live up to expectations, and so slip-year financing was introduced in 1973-74. Under slip-year financing universities were to be paid on a formula related to their enrolments in the preceding year. One effect of this change was that governments were able to see the total enrolment prior to setting the value of the basic income unit, thus providing a mechanism for limiting expenditure. In 1972 the government imposed a moratorium on capital grants for most kinds of new construction, since there was a perception that there was surplus physical capacity within the university system and that qualified applicants could still find a place in some programme somewhere. Commencing with the 1976-77 year a new formula for financing was introduced which reduced the financial impact of enrolment changes. By 1977-78 the formula produced only 50\% funding for growth in enrolment beyond that established in the base period 1974-77. Similarly universities were protected from the impact of declining enrolments. In summary, for much of the period 1960.78 governments through their financing arrangements provided strong incentives for growth in enrolment, but the period ended with a financing mechanism which encouraged stability.

While the public funding was increasing greatly, the price of education to the student in the form of tuition fees was decreasing. In Canada the proportion of university income derived from student fees fell from about $16 \%$ in $1960-61$ to less than $10 \%$. (Statistics Canada 1978, p 30) Throughout most of the 1960s tuition fees changed little and in the early 1970 s were encaptured in the formula funding mechanism by the incorporation of the "standard formula fee". The standard fee was the median of the fees charged by Ontario universities and was deducted from the funds generated by the formula funding. In 1972-73 the formula fees were raised by $\$ 100$. Following the elapse of a further five years the fees were raised again by $\$ 100$ in 1977.78 and by $5 \%$ two years later. The 
Provincial government has commissioned and received a report on tuition and other fees, and it is anticipated that a new policy will be developed. It appears unlikely that fees will be permitted to remain static and thus comprise an ever increasingly smaller proportion of the universities' revenues. Thus, for most of the period tuition fees were relatively stable which, while they may not have provided an encouragement for students to attend universities, were not a major deterrent. As the period came to a close it appeared that fee increases on a more regular basis might well be anticipated.

Expenditures on scholarships and student aid in Canada grew from $\$ 9.6$ million in 1960-61 to $\$ 384.4$ million in 1977-78. (Statistics Canada 1978, p 33) Through the provision of financial aid, accessibility was actively pursued by providing the opportunity for post-secondary education to many who had previously been unable to afford it. The Canada Student Loans Program was introduced in 1964 and amended in 1965 by the introduction of a means test. In 1966 the administration of the plan was handed over to the provinces and the Ontario Student Assistance Programme, which was designed to supplement the Federal programme, was subsequently introduced.

Both the statements of the government's policy on accessibility and the funding formula essentially leave to the universities the decision to determine who is qualified to enter, although there are some minimum stipulations related to funding. Approximately $80 \%$ of those who enter the Ontario universities as freshmen do so with qualifications obtained in Grade 13. During the period 1960-78 the term "qualified" has changed somewhat. In general an applicant must obtain the Secondary School Honour Graduation Diploma and appropriate standing on a specified group and number of subjects. In the period 1944-65 the requirements for the Honour Graduation Diploma were eight credits, from 1966-70 seven credits, and since 1971 six credits. Similarly the number of credits required for university admission has dropped from nine credits in 1966 to seven credits in 1967 and six credits in 1971. The decrease in the number of credits required was also accompanied by less specification of individual subjects being required.

Another change which had a strong impact on the number of students qualified for university admission was the abolition of departmental examinations in 1968. From Table 1 it may be seen that the proportion of Grade 13 papers passed increased dramatically from $85.2 \%$ in 1967 to $92.5 \%$ in 1968 . Similarly the proportion of those who receive the Honour Graduation Diploma who qualify for the designation "Ontario Scholar" for which an $80 \%$ average is required has increased. The proportion of the population entering Grade 13 and qualifying for the Honour Graduation Diploma increased in the period 1961-71; however it has decreased since that time.

In response to increasing concern about standards and the quality of the secondary school curriculum the Ministries of Education and of Colleges and Universities jointly launched the Interface Study which was conducted during 1975 and 1976 . Following this study increased structure in the secondary school curriculum was announced by the Ministry of Education. It appears that the concerns may have been reflected subsequently in the marking by teachers; in 1977 there was a slight decline in the proportion of Grade 13 papers passed. During the mid-1970s an increasing number of universities limited enrolments in a variety of programmes making it more difficult for applicants to gain admission to such programmes. Thus one had the coming together of a number of factors which served to limit the numbers of "qualified" applicants, which in part was responsible for the stabilizing of the intake prior to its decline in 1977. 
TABLE 1

GRADE 13 STATISTICS FOR SELECTED YEARS

\begin{tabular}{|c|c|c|c|c|c|c|c|c|}
\hline & 1 & 2 & 3 & 4 & 5 & 6 & 7 & 8 \\
\hline & $\begin{array}{c}19 \text { year } \\
\text { olds }\end{array}$ & $\begin{array}{l}\text { Grade } 13 \\
\text { prior } \\
\text { year }\end{array}$ & $\begin{array}{l}\text { SSHGD } \\
\text { awarded }\end{array}$ & $\begin{array}{l}\% \text { Grade } 13 \\
\text { papers } \\
\text { passed }\end{array}$ & $\begin{array}{l}\text { Ontario } \\
\text { Scholars }\end{array}$ & $2 / 1$ & $\begin{array}{c}3 / 1 \\
\%\end{array}$ & $\begin{array}{c}5 / 3 \\
\%\end{array}$ \\
\hline 1961 & 79,959 & $18,447^{\star}$ & $10,695 *$ & $82.2 \%$ & 383 & $23.7 \%$ & $13.4 \%$ & \\
\hline 1966 & 122,662 & 41,841 & 28,533 & $84.6 \%$ & 1,886 & $34.1 \%$ & $23.3 \%$ & $6.6 \%$ \\
\hline 1967 & & 38,963 & 26,542 & $85.2 \%$ & 2,314 & & & $8.7 \%$ \\
\hline 1968 & & 40,564 & 32,492 & $92.5 \%$ & 3,764 & & & $11.6 \%$ \\
\hline 1971 & 133,995 & 52,951 & 39,776 & $92.4 \%$ & 5,802 & $39.5 \%$ & $29.7 \%$ & $14.6 \%$ \\
\hline 1976 & 156,190 & 59,997 & 42,223 & $95.1 \%$ & 9,748 & $38.4 \%$ & $27.0 \%$ & $23.1 \%$ \\
\hline 1977 & & 61,892 & 43,128 & $94.3 \%$ & 10,075 & & & $23.4 \%$ \\
\hline 1978 & & 60,733 & 42,673 & & 9,900 & & & $23.2 \%$ \\
\hline
\end{tabular}

Sources 1: Statistics Canada Census Data

$2,3,4,5$ : Education Statistics, Ontario, Ministry of Education

* public schools only for 1960-61 school year 
45 The Impact of the Participation Rate - Whatever it is - on University Enrolment

TABLE 2

APPLICANTS AND REGISTRANTS FOR SELECTED YEARS

\begin{tabular}{|c|c|c|c|c|c|c|}
\hline & \multicolumn{3}{|c|}{ Secondary School Applicants } & \multicolumn{3}{|c|}{ Other Applicants } \\
\hline & 1. Applicants & 2. Registrants & $\%(2$ of 1$)$ & 3. Applicants & 4. Registrants & $\%(4$ of 3$)$ \\
\hline 1974 & 36,943 & 26,219 & 71.0 & 19,557 & 8,628 & 44.1 \\
\hline 1975 & 36,680 & 27,008 & 73.6 & 22,648 & 8,630 & 38.1 \\
\hline 1976 & 39,596 & 27,505 & 69.5 & 22,669 & 8,904 & 39.3 \\
\hline 1977 & 39,096 & 26,084 & 66.7 & 20,567 & 7,550 & 36.7 \\
\hline 1978 & 36,773 & 25,341 & 68.9 & 20,199 & 7,543 & 37.3 \\
\hline
\end{tabular}

Source: Admission Data System Reports. Ontario Universities Application Centre (Note: The reporting dates vary from year to year)

In addition to those admitted from Grade 13, there are other applicants who present a variety of qualifications. In these cases there is greater latitude for exercising judgement by those responsible for admissions to universities, and to some extent the decisions are influenced by the availability of spaces and number of applicants from the Grade 13 stream. The data in Table 2 show that applicants and registrants from the secondary school stream were increasing in the period 1974-76; this was accompanied by an increasing number of programmes being limited in enrolment. During that same period the proportion of other applicants who were registering was declining and at a faster rate. In 1977 there was a decrease in registrants from both groups and freshman enrolment declined. In 1978 the proportion of other applicants admitted and registered increased and preliminary indications are that this trend will be followed in 1979.

In the limited enrolment programmes, such as Engineering and Business, the admission averages required may be well above the minimum stated, and there is flexibility to adjust the required standard in accordance with demand for the programme and also in relation to what is happening in other sectors of the university. In the high demand areas like Engineering and Business, registration has not kept pace with the applications because of institutional decisions. (See Table 3) It would be interesting to know whether the large increases in these two areas in 1978 were designed to offset declines in other areas.

The period has also seen a large increase in the female participation rate and it is only because of the growing female participation rate that total enrolment in Canada has continued to rise in the period 1971-76. (Statistics Canada 1978, p 16) The participation rate for males peaked in the early 1970 s, although it still stands higher than the participation rate for females. There has been growth in the number of foreign students attending Ontario universities to the point where there are $4 \%$ of undergraduates now who are foreign students. A comparison with the earlier years in the period is not possible because of the lack of data. In 1976 the Ontario government introduced a higher formula fee for students studying at provincial universities on student visas, and nearly all universities were forced to pass on this fee to foreign students. This was followed by a decrease in the 
TABLE 3

APPLICANTS AND REGISTRANTS FOR BUSINESS AND ENGINEERING

\begin{tabular}{l|cc|cc}
\hline \multirow{2}{*}{} & \multicolumn{2}{|c|}{ Business } & \multicolumn{2}{c}{ Engineering } \\
\cline { 2 - 5 } & Applicants & Registrants & Applicants & Registrants \\
\hline 1974 & 3,869 & 2,438 & 4,707 & 3,005 \\
1975 & 4,643 & 2,461 & 5,733 & 2,984 \\
1976 & 5,392 & 2,925 & 5,937 & 2,879 \\
1977 & 5,873 & 3,166 & 5,786 & 2,832 \\
1978 & 6,602 & 3,649 & 6,101 & 3,244 \\
\hline
\end{tabular}

Source: Admission Data System Reports. Ontario Universities Application Centre

(Note: The reporting dates vary from year to year)

number of foreign students entering the universities of the province. (Statistics Canada 1978, p 60) Subsequent adjustments of tuition fees have not included adjustments of the fee required of foreign students so that the size of the differential has diminished.

The other major trend which has occurred between 1960 and 1978 has been a shift away from arts and science programmes to the professional programmes. This shift, however, has not been a constant shift. The proportion registered in Engineering actually dropped during the 1960 s until the early 1970 s, and increased thereafter to its present high level. Education is a professional field in which the demand is decreasing in response to the decreased need for teachers at the elementary and secondary levels. The shift to an increasing proportion of students in the professional programmes of universities could have major impact upon the character of institutions, but past experience would suggest that demand for such programmes could wane just as rapidly as it waxed.

\section{Participation Rates and the 18 to 24 Age Group}

The participation rate is a ratio, which commonly is derived by dividing the number of full-time students by the size of the 18 to 24 age group. In modern society we have a plethora of data and in our search to reduce these in number we try to create "meaningful" ratios which are designed to tell us what is "really happening". A further characteristic of these ratios, such as "miles per gallon", is that they become measures of performance. A higher "miles per gallon" ratio becomes good in an energy-starved world, and a lower participation rate is seen to be an indicator that university education is in disfavour or is perceived to be irrelevant.

In many cases these ratios are dangerous on at least two counts:

1. the numerator and denominator may be inappropriately combined, and, when the ratio is translated into a measure of performance, the concept of a ratio may be translated into simplistic political slogans such as "more scholar for the dollar"; and 
47 The Impact of the Participation Rate - Whatever it is - on University Enrolment

2. the creation of the all purpose ratio serves to mask the failings and inconsistencies in the data used to create the numerators and denominators. As one reviews the past, it is easy to see that the numerator, full-time students, has varied, because

i) groups of students may have been included or excluded (e.g. education students);

ii) definitions of "full-time" have varied in time, among institutions, and by user; and

iii) count dates have varied.

Even if one were to define "full-time", it would be virtually impossible to reconstruct past data to fit the definition.

In addition to being used as measures of performance, ratios take on another use, that of projecting the future value of a second variable where the first variable has already been projected. By merely changing the all-important ratio, despite all its failings, one can readily generate a variety of future scenarios. Extending the use of the magic ratio in this way takes one yet another step away from the original data and the failings inherent in them. It may also blind one to the possibility of foreseeing a major structural change, such as a change in the age profile of those attending university.

The use of a participation rate in connection with existing demographic projections to generate projected enrolments has other limitations too. For most of the period 1960-78 there was an attempt to match the supply of places to the demand for them either by creating new institutions or expanding existing ones, so that any participation rate was measuring primarily demand which was being stimulated by changing admission requirements, increased financial aid, etc. Towards the end of the period spaces were being limited in an increasing number of programmes and government funding no longer encouraged growth, so that the rate was influenced more by supply of spaces than it had been. When participation rates are used and projected, there is a tendency to look only at the demand and to ignore the supply and the interaction between the two. Enrolment in university education is not compulsory, and is dependent both on the inclination of a person to participate and on that of another to decide whether the first may participate. Most systems have built-in intertia which resists change. Thus, an increase in those who wish to enrol may be off-set by a smaller proportion being offered the chance to do so, and vice-versa. Another possibility is that, if the demand in one area falls below the supply, the supply may be increased in another area which is oversubscribed; for example, falling enrolments in Science may be off-set by increasing the supply of places in Engineering. Obviously this is limited by the ability of institutions to reallocate specialized resources, and in the longer term by the opportunities for engineering graduates.

Most projections are essentially mechanistic and assume that past experience or someone else's experience will be the best guide. What is required is a more rigorous analysis of the factors which have caused past experiences, and some assessment of how these factors might change or what factors may become important. The result of such a process may be less precise - and, therefore, unacceptable to many - but may serve to define better the possibilities and options that are available.

Before concluding this section on participation rates, the use of the 18 to 24 age group for describing the rate warrants some examination. Why is this group so important? The standard answer is "Because most full-time undergraduates are in this age group." $-89 \%$ 
GRAPH 1

ONTARIO POPULATION BY SELECTED AGES

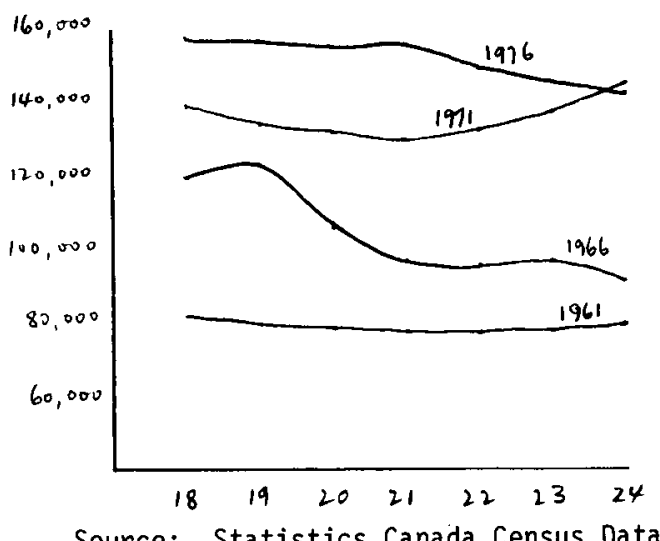

in Ontario. (Statistics Canada, 1979 p 46) The same statement would be true of other groups such as 19 to $26(87.5 \%)$, or 19 to $22(79 \%)$.

The use of any of these age groups would be acceptable if the age profile of the population were constant and the participation rates for different ages continued to be in the same proportions. An examination of Graphs 1 and 2 reveals that this is not the case. Participation is highest among those from 19 to 21 , and the age profile of the 18 to 24 age group has varied in the different census years. In 1976 those of ages, 19, 20 and 21 constituted a higher proportion of the total 18 to 24 age group than was the case in 1971 . Had the participation rate by single year of age been the same in the two years, the 1971 participation rate for the 18 to 24 age group would have been lower than in 1976 .

Another consequence of using a broad band such as the 18 to 24 group is that changing trends are masked. Population projections for Ontario show that the size of the 18 to 24 age group may be expected to peak in 1983. (Clark, Devereaux, Zsigmond, 1979 p 121) Even as early as mid-1975 Ministry of Education projections were showing the peak in Grade 13 enrolment occurring in 1977-78 (Ministry of Education, 1975), so that it was not unreasonable to expect that Year I enrolment in the universities would peak in 1978 . 79 rather than 1980-81 commonly quoted, and that total undergraduate enrolment would peak perhaps two years later. In fact the peak in university enrolment occurred earlier for reasons unrelated to demography, but the use of the 18 to 24 age group tends to predict enrolment changes related to demographic changes occurring later than would other methods.

\section{8-1996: The Years of Decline?}

Full-time undergraduate enrolment peaked in 1976-77, not because that year coincided with a peak in the size of the population most likely to attend, but because a smaller 
GRAPH 2

AGE PROFILE OF FULL-TIME UNDERGRADUATES IN ONTARIO, 1977-78

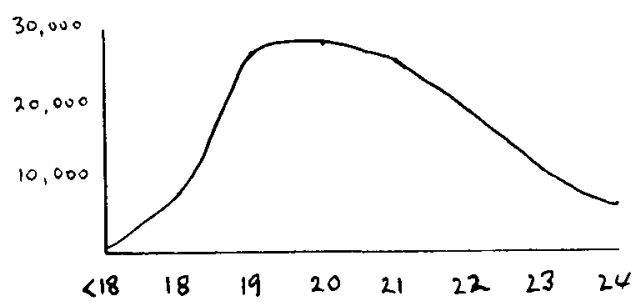

Source: Universities: Enrolment and Degrees 1977 Statistics Canada $\mathrm{p} 46$.

proportion of that group attended. Despite the failings of the usual participation rates and the 18 to 24 age group, it is interesting to note that the decline in the size of the 18 to 24 age group from 1976-77, the peak enrolment year, to 1996, the population trough year, is but a mere $7.9 \%$. (Projection 4, Clark, Devereaux, Zsigmond, 1979) If instead one were to use 18 to 21 , the decline would be $11.9 \%$; on the other hand using Projection 3 and the 18 to 24 group produces a decline of only $6.4 \%$.

When changes of this magnitude spread over a twenty - year period are compared with enrolment declines of $2.8 \%$ in $1977-78$ and $2.9 \%$ in $1978-79$, it is obvious that the demographic changes will not be the over-riding influence on university enrolments. The demographic changes in the period 1960-78 were greater, and admittedly easier to cope with since the age group was growing. A rapidly growing age group can mask minor dips in the proportion attending. Perhaps the current concern with the level of enrolment is not warranted, and stems from our relatively recent experience with funding tied by a formula directly to the current enrolment. Already that formula has been modified to reduce the financial impact of fluctuations in enrolment. If adequate funding were available, a drop in enrolment could be accompanied by a decreased student:staff ratio. Thus funding not enrolment is the major problem. However, the level of enrolment retains its influence because of the property of ratios whereby they are used to measure performance and their use in the political process. Declining participation can be interpreted by government as declining public favour for universities which in turn influences the funding decisions.

The preoccupation of the universities with the projected decrease in numbers of young persons during the 1980 s and 1990 s, the declines in enrolment that have already taken place, and funding increases which have not matched inflation have lead to a siege mentality in which the main concern has been the reduction of expenditure and survival. This has been aggravated by the way in which the value of a university education has been discounted in the news media; there has been little response from the universities, except perhaps to answer specific charges which puts the universities in a reactive position, where they are fighting on a battle ground not of their choosing. Most of the promotion of the universities is still directed towards the secondary schools and is conducted by relatively junior staff 


\section{A.L. Darling}

who themselves are not far removed from their student days and may be in their first job, so that they have not had time to reflect on their own educational experience. Given the projections of secondary school enrolments, the activities should be directed to a broader corss-section of the population, and in the case of secondary school students the influence of parents should not be ignored. The task of "promotion" is too important to be left to the professional promoters who are too junior. All members of the universities by their words and actions project an image of the utility and relevance of the institution to which they belong. If they are apologetic or indifferent, this will be picked up by the public.

The universities have not found a way to answer the public criticism, and until they do so this will be reflected in enrolment. Perhaps this is related to a confusion of objectives for the general arts and science programmes in particular. During the 1960 s university education was seen as an investment in human capital and the return to the individual was in the form of higher salaries; this view was widely espoused and subsequently when graduates did not obtain employment that matched their expectations, there was increasing disenchantment and talk of unemployed graduates. Surveys suggest that unemployed university graduates are fewer in proportion to their peers than are unemployed persons in groups; perhaps their expectations were higher and they have been better trained to be articulate.

The public perception and perceived employment prospects will continue to influence participation. Just as it was folly to promote university education solely on the basis of increased earning potential, likewise it is folly to say that employment prospects are irrelevant. Particularly in the general programmes it is necessary to define the objectives of the programmes and in describing these programmes to potential students to relate these objectives to life. It is of course essential that the programmes be designed in such a way that the objectives are in fact met.

What are the employment prospects for graduates? They are of course related to the economy and in the short term there will continue to be large numbers of new entrants to the labour force. Traditionally many of the arts and science graduates have entered teaching via education programmes, in which enrolment is now being curtailed. With few teaching positions available and a situation which has discouraged part-time employment, there has been less teacher mobility and an unwillingness to leave a position, which in turn has further reduced teacher openings. Alternatives such as job-sharing are now being discussed and may prove attractive to a sufficiently large proportion to alleviate somewhat the current gloom about prospects for teaching employment. The prospects for science graduates may be improved if the Federal government does live up to its past statements on research and development. Changes like these and a decreased supply of graduates in the future resulting from the lower intake may brighten employment prospects by the mid-1980s by which time the annual number of new entrants to the labour force will have decreased. However, the optimistic view must be counterbalanced by an acknowledgement that many arts and science graduates have been employed by government, growth of which is being curtailed.

The recent trend has been towards greater enrolment in professional programmes, but this was not the case for all the period 1960-78. Some of the professions supported by these programmes may become oversubscribed just as education has, particularly if much of the funding comes from the public purse as it does for the arts, recreation programmes, 
51 The Impact of the Participation Rate - Whatever it is - on University Enrolment

health care, and libraries. A result might be more concentration on professional upgrading with short courses of up to a year's duration, as is being done increasingly in education. Alternatively, interests may change reflecting changes in society. Concerns about quality of life or "the small is beautiful" approach may catch the imagination and revive an interest in arts programmes which have been languishing in recent years. It would certainly be contrary to our past experience with engineering enrolments, for example, to expect the trend to increasing applicants for professional programmes to continue indefinitely.

Future enrolment will be affected by the programmes offered. Part of the increase in enrolment between 1960 and 1978 resulted from new programmes or the lengthening of existing programmes. It is unlikely that the programmes of 1996 will be the same as those of 1978 . The more an institution is affected by declines in enrolment the more it is likely to re-examine and modify its programmes in its attempt to survive. Clues as to where future degree programmes may be developed may exist in the diploma or non-credit offering of institutions. Perhaps the needs of the banking community or the law-enforcement agencies are examples of grounds for new seeds. Much education is conducted in the private sector through company training programmes and independent agencies such as consulting firms. while it may be unrealistic to expect that such programmes might be transferred to the universities, there may be opportunities for universities to work cooperatively with the private sector by offering their teaching and research expertise. This may be limited by the fact that the opportunities often reside in those areas like Business where qualified university teachers are in shortest supply.

Comparison of 1960 and 1978 enrolments is distorted by the effects of new institutions and new programmes, so that the enrolment figures were in fact measuring different things. One might expect then that 1996 enrolments will be a measure of something different from those of 1978. The changes in distribution of undergraduates between general and profes. sional programmes, if continued, could significantly alter the nature of some institutions. It should also be noted that increases and decreases in enrolment are not spread evenly among institutions. A small drop in the intake to the system of universities may result in relatively large drop for individual institutions. It is these institutions which may change most in their character. Just as the creation of new institutions was in many cases politically motivated, so the possibility of closure of institutions must be assessed in terms of the political significance. Recent experience such as with hospital closures suggests closure is unlikely and that direct action by government to change the nature of institutions is unlikely. The impetus for change will have to come from within individual institutions, although such changes may be encouraged or discouraged by government through funding policies which can have a steering effect. (For example, the decision to fund new programmes resides with government and its agencies.) The steering effect of funding policies can be seen from the initial impact of formula funding which encouraged growth because marginal costs were below marginal increments in funding; the decision to discount growth subsequently served to put a brake on growth. The changes in institutions are most likely to be incremental rather than massive shifts, since enrolment changes will be spread over a number of years and funding policies spread out over a number of years the financial impact of enrolment changes. The changes are likely to come about by the closure of selected programmes, departments, or colleges; by the regrouping or merging of organizational units within institutions, or selectively, between institutions; and by the creation of new programmes. 


\section{A.L. Darling}

The speed of such changes will be limited by the presence of highly specialized faculty, and an awareness that the past has displayed fluctuations in the areas of interest to students. The popularity of disciplines wax and wane in response to the latest "fad" and it would be unwise to try to staff an institution in response to short-term fluctuations. Attempts must be made to try to protect the weak in the lean years for the long-term good of the institution.

The determination of who is qualified to enter universities is a prerogative of the universities, although the government may specify which groups qualify for funding. Approximately $80 \%$ of those who enter do so on the basis of Grade 13 qualifications and with the Secondary School Honour Graduation Diploma. The number of credits required for admission has dropped from nine to six, and for the Diploma from eight to six. The number of Grade 13 papers passed rose from $82.2 \%$ in 1961 to $95.1 \%$ in 1976 , while the proportion of those obtaining the Honour Graduation Diploma who were named Ontario Scholars grew from $6.6 \%$ in 1966 to $23.4 \%$ in 1977 . These changes have enabled some students to qualify for admission who probably would not have done so previously. Further relaxation of standards would appear unlikely, although it should be noted that a smaller proportion of the population is continuing in secondary school to obtain the Honour Graduation Diploma. The Diplomas awarded in proportion to the number of 19 year-olds in Ontario dropped from $29.7 \%$ to $27.0 \%$ between the census years 1971 and 1976. In addition a greater proportion of Grade 13 graduates have been entering colleges rather than universities. A reversal of either or both these trends could increase the number of qualified applicants; a change from the $27.0 \%$ of 1976 back to the $29.7 \%$ of 1971 would represent a $10 \%$ shift, which in itself could offset the projected decline of the university age group between 1976 and 1996.

The remaining $20 \%$ of the freshmen present a variety of qualifications which by their nature require more in the way of subjective judgement on the part of those making admission decisions. Thus, anticipated declines in those with Grade 13 qualifications can be offset somewhat by this group, which includes mature students, those with foreign qualifications, those who have studied in colleges, or in other provinces, etc. Those with foreign qualifications who have registered are fewer since the introduction of the higher formula fee by the government in 1976. While fees for domestic students increased in 1977 and 1979, the foreign student fees remained unchanged so that the differential has been reduced. External factors like the level of fees, currency fluctuations, and changes in immigration patterns in the future could well affect the number of foreign applicants. Of approximately the same size is the body of students admitted from Quebec, which more than doubled between 1975 and 1978. Changing social and political situations in that province and the spaces available in Ontario universities will no doubt influence the number of applicants. While out-of-province fees have not been a feature of Canadian education, the possibility in the long term should not be ruled out particularly since the Federal government is no longer involved in the funding in the same way as it was under the Fiscal Arrangements Act of 1967. Another component is comprised of those with qualifications from the Colleges of Applied Arts and Technology, a population which is growing and a greater proportion of whom are Grade 13 graduates. While the number entering Year 1 of the universities has dropped from 983 in 1976 to 765 in 1978, the number may increase in the future, particularly if increased inter-institutional co-operation facilitates 
53 The Impact of the Participation Rate - Whatever it is - on University Enrolment

TABLE 4

APPLICANTS AND REGISTRANTS IN SELECTED PROGRAMMES

\begin{tabular}{|c|c|c|c|c|c|c|c|c|c|c|}
\hline \multirow[b]{2}{*}{ Programme } & \multicolumn{2}{|c|}{1974} & \multicolumn{2}{|c|}{1975} & \multicolumn{2}{|c|}{1976} & \multicolumn{2}{|c|}{1977} & \multicolumn{2}{|c|}{1978} \\
\hline & A & $R$ & A & $\mathrm{R}$ & A & $\mathrm{R}$ & A & $\mathrm{R}$ & A & $\mathrm{R}$ \\
\hline Engineering & 4707 & 3005 & 5733 & 2984 & 5937 & 2879 & 5786 & 2832 & 6101 & 3244 \\
\hline $\begin{array}{l}\text { Physical } \\
\text { Education }\end{array}$ & 2619 & 1672 & 2871 & 1644 & 3224 & 1672 & 3700 & 1617 & 2881 & 1496 \\
\hline Business & 3869 & 2438 & 4643 & 2461 & 5392 & 2925 & 5873 & 3166 & 6602 & 3649 \\
\hline Nursing & 1390 & 542 & 1426 & 545 & 1464 & 501 & 1144 & 482 & 1044 & 483 \\
\hline
\end{tabular}

Source: Admission Data System Reports Ontario Universities' Appiication Centre.

$A=$ Applicants $\quad R=$ Registrants

(Note: The reporting dates differ so there are some data inconsistencies.)

the transfer of credit. The applicants who do not present Grade 13 qualifications, therefore, represent a group which could be influenced by a variety of factors, and a group to which universities have not traditionally geared their promotional activities. This group of applicants is used somewhat to offset anticipated declines in Grade 13 graduates. It is questionable, however, whether a major decline in the enrolment of the principal group could be offset by increases in these secondary groups.

In some disciplines the number of university spaces is limited and the averages required for admission exceed the normal minimum average of $60.0 \%$. Thus, a decrease in applicants may not necessarily result in a corresponding decrease in registrants. Furthermore, if there is a general decrease in applicants, institutions may seek to offset anticipated decreases in some areas by increasing the number of spaces in "limited enrolment programmes". Some of the areas with limited spaces in recent years have been Business, Engineering, Nursing, and Physical Education. From Table 4 it is apparent that in the period 1974-78 the number of registrants did not rise in proportion to the number of applicants. In the case of Business and Engineering there were steady increases in applicants with some increases in registrants for Business, but no increase in Engineering during the period to 1977. In 1978 there were increases in both registrants and applicants in these two programmes, apparently in an attempt to offset decreases in other programmes. Although there was a large drop in Nursing applications in 1977 in the face of media publicity about unemployed nurses, there was virtually no change in registrations. However, in the case of Physical Education, after some years of increasing applications and stable registrations, a downturn in applications in 1978 resulted in a lower registration. It appears, therefore, that some programme areas can withstand decreases in applications without the number of registrations dropping, but this is not true in all cases.

While data about new entrants are reasonably easily accessible, it is difficult to obtain 
data on retention rates and the effects of changing academic standards. Upper year students outnumber Year 1 students, so their numbers have a large impact on total enrolment, and yet there is a lack of data. The decision to withdraw or to seek to re-enter is made by a student, but the institutions control standards and the decisions to permit a student to continue or to re-enter after an absence. These decisions are affected both by the prevailing academic climate and the perceived availability of spaces, and the decisions can moderate somewhat enrolment shifts, though to a limited extent, for a decision to re-admit a student cannot be made unless he or she has first applied.

The costs of university education are both public and private, and the private costs borne by the student are both direct and indirect. For the period $1960-1976$ the real direct costs of tuition fees were decreasing for the student, as tuition fees remained fairly constant and incomes rose. Other direct costs rose less than did incomes, but the indications for the future are that tuition fees will continue to rise on a more regular basis and perhaps at a faster rate. As long as inflation remains high the other direct costs will mount. While few persons contemplating the possibility of university education would sit down and prepare a rigourous economic cost/benefit analysis, there is no doubt the applicants do consider the potential benefits and costs. The benefits have probably been discounted by the publicity given to the unemployed and underemployed graduates. (It may also be true that those who use as counter-argument the unemployment statistics by educational qualifications which show university graduates with the highest employment rate are overstating the benefits. The statistics are not adjusted for age and ability in many cases. In the 15 to 24 age group, university graduates are older and may have more inate ability which would have won them jobs even if they did not attend university.) What is important is not so much the reality but the perception of the employability of the university graduate. If the perception changes to a more favourable view, then the influence on enrolment may be reflected by an increased participation. The decision to enrol must be made almost five years prior to one's entering the employment market, so that the reality one faces may be far removed from the prior perception.

During the 1960s and early 1970s enrolment growth was encouraged by government and supported financially at both the federal and provincial levels. Funding was related to enrolment and increasing tax revenues enabled governments to fund the growth. Modifications to the funding formula enabled the governments to control their expenditure, and influenced universities to limit their enrolment growth. The 1970 s closed with governments seeking to limit the growth in public expenditures and reduce deficits, so that increases in the grants to public institutions were below the rate of inflation. It may be anticipated that this will continue, and with the discounting of income units for enrolment changes the incentives for major expansion of enrolment is limited. However, there may be increased competition by institutions in attempts to maintain positions comparable to the present by ensuring increases or decreases in enrolment close to the provincial average so that they may at least maintain their shares of the diminishing pot. The size of that pot will be determined by the relative priorities of the demands on government and the size of constituencies represented. Declining enrolments would reduce the influence the universities can bring to bear in the political process, and other constituencies may gain in influence. At least in the shorter term increases in government expenditures will continue to trail the rate of inflation, and those dependent on government aid will be treated 
55 The Impact of the Participation Rate - Whatever it is - on University Enrolment

accordingly. The primary problem facing the universities will, therefore, be financial. The level of enrolment will serve merely to define how large the financial problem is, but there is no reason why the changes in enrolment must follow the pattern established by the 18 to 24 age group. The examination of the factors which will determine the participation rate suggests ways in which the rate can be influenced both by the universities themselves and by other forces. Some of the changes suggested would serve to increase the rate and some to decrease it.

\section{Conclusion}

In comparison to the changes in the period 1960-78, the change in the number of young people who are of the age most likely to attend university is relatively small for the period 1978-96. The actual level of university enrolment will be much more influenced by the participation rate - however it may be defined - than it was in the earlier period. Because the size of a particular age-group is projected to decline by over $20 \%$ between 1982 and 1996, it does not follow that university enrolment must fall by the same amount. In fact enrolment could fall by far more, ,or it could even rise. There is a current mood of fatalism which may not be warranted.

Among the factors examined earlier a number are combining to reduce or limit enrolment, such as:

1. a perception of poor employment prospects for graduates;

2. limitations of enrolment in selected areas; and

3 . a decrease in the proportion of the population graduating from Grade 13.

In the first case universities could work to modify the current perceptions, and in the second they may change policies. A change in the third factor, which may be dependent on the first, would have a large influence on enrolment. The universities can, therefore, to some extent influence the level of enrolments by their own actions, and in many cases are only learning how to do this. Decreases in enrolment do not have to be inevitable, although they are probable if the status quo is maintained. Enrolment changes of themselves will not be the direct cause of the major problems universities will face, but may be influential in the political process by which funding decisions are made.

\section{REFERENCES}

Clark, W., Devereaux, M.S., and Zsigmond, Z., The Class of 2001. Statistics Canada, Ottawa, February 1979.

McMaster University. A Submission to the Ontario Council on University Affairs. Hamilton, April 1977. Ministry of Colleges and Universities. The Potential Impact of Regional High School Enrolment Changes to 1986 on Universities and Colleges of Applied Arts and Technology. Toron to, November 1978.

Ontario Council on University Affairs. Third Annual Report, 1976-77. Toronto, March 1977.

Ontario Council on University Affairs. Fourth Annual Report, 1977.78. Toronto, March 1978.

Ontario Council on University Affairs. Fifth Annual Report, 1978-79. Toronto, March 1979.

Statistics Canada. From the Sixties to the Eighties: A Statistical Portrait of Canadian Higher Education. Ottawa, August 1978. 
56 A.L. Darling

Statistics Canada. Universities: Enrolment and Degrees 1977. Ottawa, March 1979.

Zsigmond, Z., et al., Future Trends in Enrolment and Manpower Supply in Ontario. Statistics Canada, Ottawa, October 1976. 